\title{
PENGARUH MOTIVASI KERJA DAN LINGKUNGAN KERJA TERHADAP KINERJA KARYAWAN PADA HOTEL SEMAGI MUARA BUNGO
}

\author{
Yudhi Novriansyah, Ahmad Yusuf Al-Aziz \\ Program Studi Manajemen Fakultas Ekonomi \\ Universitas Muara Bungo
}

\begin{abstract}
ABSTRAK
Tujuan dari penelitian ini untukmengetahui pengaruh yang signifikan antara motivasi kerja dan lingkungan kerja terhadap kinerja karyawan padaHotel Semagi Muara Bungo secara parsial dan simultan. Jumlah populasi sebanyak50 orang dan sampel adalah berjumlah 50 orang dengan metode penarikan sampel mengunakan Sampling Jenuh.

Berdasarkan hasil pengolahan data, diperoleh hasil persamaan regresi linier berganda sebagai berikut $: \mathrm{Y}=16,926+1,082 \mathrm{X}_{1}+0,353 \mathrm{X}_{2}+\mathrm{e}$ dan hasil dari Uji-t menunjukkan bahwa variabel motivasi kerja diperoleh nilai hitung $=8,974$ dan $\mathrm{t}_{\text {tabel }}=2,012$ pada tingkat signifikasi 0,05 maka keputusannya adalah $\mathrm{H}_{0}$ ditolak Ha diterima, maka dapat di simpulkan bahwa motivasi kerja berpengaruh signifikan terhadap kinerja karyawan dan variabel lingkungan kerja dengan kinerja karyawan diperoleh nilait $t_{\text {hitung }}=3,117$ dan $t_{\text {tabel }}=2,012$ pada tingkat signifikasi 0,05 maka keputusannya adalah $\mathrm{H}_{0}$ ditolak $\mathrm{Ha}$ diterima, maka dapat di simpulkan bahwa lingkungan kerja $\left(\mathrm{X}_{2}\right)$ berpengaruh signifikan terhadap kinerja karyawan dan kemudian berdasarkan uji secara simulatan secara bersama-sama (serentak) variabel independent yaitunilai $F_{\text {hitung }} 40,599>\mathrm{F}_{\text {tabel }} 3,20$. Dengan demikian hipotesis $\mathrm{H}_{0}$ ditolak dan $\mathrm{H}_{\mathrm{a}}$ diterima. Artinya, secara bersama-sama (serentak) variabel independent yaitu motivasi kerja $\left(\mathrm{X}_{1}\right)$ dan lingkungan kerja $\left(\mathrm{X}_{2}\right)$ berpengaruh signifikan terhadap variabel dependent $(\mathrm{Y})$ yaitu kinerja karyawan. Berdasarkan hasil pengolahan data variabel motivasi kerja dan lingkungan kerja memberi pengaruh terhadap variabel kinerja karyawan adalah sebesar $66,3 \%$ dan sisanya sebesar $33,7 \%$ dapat dijelaskan oleh faktor-faktor lain diluar dari penelitian ini.
\end{abstract}

Kata Kunci : Motivasi Kerja, Lingkungan Kerja dan Kinerja Karyaw

\section{PENDAHULUAN}

Perusahaan dapat berkembang merupakan keinginan setiap individu yang berada di dalam perusahaan tersebut, sehingga diharapkan dengan perkembangan tersebut perusahaan mampu bersaing dan mengikuti kemajuan zaman. Keberhasilan suatu perusahaan dalam mencapai tujuannya tergantung pada prestasi kerja sumber daya manusia yang dinilai langsung oleh atasan/pimpinan perusahaan.

Saat ini sangat disadari bahwa sumber daya manusia merupakan masalah perusahaan yang paling penting, karena dengan Sumber Daya Manusia (SDM) menyebabkan sumber daya yang lain dalam perusahaan dapat berfungsi/dijalankan, pada dasarnya apa yang dilakukan oleh perusahaan terhadap karyawannya akan mempengaruhi kinerja karyawan tersebut. Kinerja merupakan dukungan untuk mencapai tujuan perusahaan karena keberhasilan sebuah perusahaan sangat bergantung dari baik dan buruknya kinerja karyawan di perusahaan tersebut, di mana setiap karyawan merupakan motor bagi berjalannya sebuah perusahaan dalam menjalankan semua aktivitasnya dan hal 
ini akan berkaitan dengan motivasi karyawan tersebut dalam bekerja.

Berdasarkan uraian diatas adapun yang menjadi fenomenanya adalah motivasi kerja karyawan belum bisa dikatakan baik sedangkan lingkungan kerja sudah sesuai dengan ketentuan yang telah ditetapkan, namun jumlah tamu dari tahun ke tahun selalu mengalami peningkatan meskipun hanya satu kali terjadi penurunan, penulis menduga bahwa besar pengaruh dan motivasi kerja dan lingkungan terhadap kinerja karyawan, untuk itu penulis menetapkan judul penelitian ini adalah "Pengaruh Motivasi Kerja dan Lingkungan Kerja Terhadap Kinerja Karyawan Pada Hotel Semagi Muara Bungo".

Beberapa faktor penting yang mempunyai pengaruh terhadap motivasi kerja antara lain kebutuhan-kebutuhan pribadi, tujuan-tujuan dan persepsipersepsi orang atau kelompok yang bersangkutan, dengan cara apa kebutuhan serta tujuan tersebut dapat terealisasi. Ini berarti apabila karyawan menyukai pekerjaan, mereka menganggap bahwa tugas mereka penuh tantangan, dan umumnya mereka akan berusaha sekuat tenaga untuk melaksanakan pekerjaan mereka secara antusias, namun apabila karyawan tidak termotivasi maka kinerja karyawan tidak dapat maksimal dan tujuan perusahaan tidak dapat tercapai.Salah satu upaya yang dapat dilakukan untuk meningkatkan kinerja karyawan adalah dengan cara memberikan motivasi. Pimpinan perlu memberikan motivasi dan arahan kepada karyawanya agar dapat bekerja dengan baik.

Hotel Semagi yang beralamat di Jln. Lintas Sumatera No. 68Muara Bungo, tidak lagi sebagai institusi yang bergerak dalam bidang pelayanan jasa perhotelan yang hanya sekedar menerima tamu untuk menginap, tetapi mereka juga menyediakan fasilitas pendukung pelayanan jasanya, dengan menawarkan pelayanan superior dan sejumlah fasilitas kepada para tamu hotel, Hotel Semagi berkomitmen untuk menjaga kenyamanan penginapan semaksimal mungkin. Hotel ini menyediakan akses ke sejumlah pelayanan, termasuk coffee shop, ruang santai bersama/area menonton TV, bar tepi-kolam, transfer bandara/hotel, dry cleaning, fasilitas rapat, layanan antar jemput, fit nes, lift, restoran dengan semua fasilitas yang ada tentunya hotel semagi juga membutuhkan sumber daya yang handal dan propesional terhadap pekerjaan yang akan di kerjakan. Adapun jumlah karyawan pada Hotel Semagi Muara Bungo dapat dilihat pada tabel berikut ini

Jumlah Karyawan Hotel Semagi Muara BungoTahun 2014 s.d 2018

\begin{tabular}{|c|c|c|c|c|}
\hline No & Tahun & $\begin{array}{c}\text { Jumlah } \\
\text { Karyawan }\end{array}$ & $\begin{array}{c}\text { Selisih Jumlah } \\
\text { Karyawan pertahun }\end{array}$ & $\begin{array}{c}\text { Persentase } \\
(\%)\end{array}$ \\
\hline 1. & 2014 & 62 & - & - \\
2. & 2015 & 58 & $(4)$ & $(6,89)$ \\
3. & 2016 & 60 & 2 & 3,33 \\
4. & 2017 & 56 & $(4)$ & $(7,14)$ \\
5. & 2018 & 50 & $(6)$ & $(12)$ \\
& & & & \\
\hline
\end{tabular}

Sumber : Hotel Semagi Muara Bungo, 2018

Dari tabel diatas dapat lihat bahwa jumlah karyawan mengalami peningkatan dan penurunan dimana pada tahun 2014 jumlah karyawan sebanyak 62 orang, pada tahun 2015 menurun menjadi 58 orang atau 6,89\%, pada tahun 2016 meningkat 
lagi menjadi 60 orang atau 3,33\%, kemudian pada tahun 2017 menurun sebanyak 56 orang atau sebesar 7,14\% dan tahun 2018 juga mengalami peningkatan yaitu sebanyak 50 orang atau $12 \%$.

Berdasarkan data diatas peningkatan dan penurunan jumlah karyawan diduga disebabkan oleh yang pertama karyawan belum termotivasi untuk menyelesaikan pekerjaan yang lebih baik karena perusahaan ini masih kurang dalam memberikan dorongan pada karyawan untuk memiliki kinerja yang lebih baik atau kebutuhan akan prestasi, dan yang kedua kebutuhan kekuasan dalam perusahaan ini karyawan harus melalui proses yang panjang untuk peningkatan jabatan yang mana setiap karyawan mempunyai target pekerjaan yang harus diselesaikan kadangkala hal ini membuat jenuh karyawan sehingga karyawan berusaha mencari pekerjaan yang lain, yang ketiga kebutuhan akan afiliasi (need for affiliation ) merupakan dorongan untuk berinteraksi dengan orang lain baik dengan atasan maupun dengan rekan sekerja yang mana karyawan pada perusahaan masih terkesan bersifat invidualisme atau personal karena setiap karyawan mempunyai target masingmasing dalam bekerja setiap bulannya dengan bidang pekerjaan atau program kerja yang sudah ditetapkan.

Berdasarkan pengamatan awal masing-masing karyawan sudah disesuaikan dengan bidang pekerjaan yang diberikan, namun demikian masih ada karyawan yang belum termotivasi dalam meningkatkan kinerja yang lebih baik, jika dilihat dari tingkatkinerja karyawan belum bisa dikatakan optimal, hal ini dapat dilihat dari jumlah tamu yang datang untuk menginap pada Hotel Semagi Muara Bungo, untuk lebih jelas dilihat pada tabel berikut ini :

\section{Jumlah Tamu Pada Hotel Semagi Muara BungoTahun 2014 s.d Tahun 2018}

\begin{tabular}{|c|c|c|c|c|}
\hline No & Tahun & $\begin{array}{c}\text { Jumlah Tamu } \\
(\text { Orang })\end{array}$ & $\begin{array}{c}\text { Selisih Jumlah } \\
\text { Tamu Pertahun }\end{array}$ & $\begin{array}{c}\text { Persentase } \\
(\%)\end{array}$ \\
\hline 1. & 2014 & 7.061 & - & - \\
\hline 2. & 2015 & 8.191 & 1.130 & 22,65 \\
\hline 3. & 2016 & 10.589 & 2.398 & $(0,74)$ \\
\hline 4. & 2017 & 10.511 & $(78)$ & 6,34 \\
\hline 5. & 2018 & 11.222 & 711 & \\
\hline
\end{tabular}

Sumber : Hotel Semagi Muara Bungo,2018

Dari tabel diatas dapat dilihat jumlah tamu pada tahun 2014 jumlah tamu7.061orang, tahun 2015 meningkat sebanyak 8.1910rang dengan persentase $13,80 \%$, tahun 2016 jumlah pelanggan mengalami peningkatan yaitu sebesar 10.589 orang atau $22,65 \%$ sedangkan pada tahun 2017 mengalami penurunan sebesar 10.511 orang atau (78)\% sedangkan pada tahun 2018 mengalami peningkatan sebesar 6,34\%.

Motivasi adalah suatu keinginan yang dapat dicapai melalui hasil kerja yang optimal. Seandainya motivasi kerja kurang maka kinerja karyawan juga idak dapat terlaksana semaksimal mungkin, lingkungan kerja sangat berpengaruh 
terhadap kinerja karyawan dimana karyawan tidak akan mungkin dapat melakukan pekerjaan sebagaimana yang diharapkan tanpa ditunjang oleh lingkungan yang mendukung dan kenyamanan karyawan didalam menjalankan pekerjaan sehari-hari sangat tergantung pada lingkungan tempat mereka bekerja. Jika ada hal-hal yang menganggu pada lingkungan tempat karyawan bekerja maka secara langsung akan berdampak buruk pada konsentrasi bekerja yang pada akhirnya berpengaruh terhadap kinerja.Berdasarkan keterangan diatas dapat digambarkan kerangka konseptual sebagai berikut :

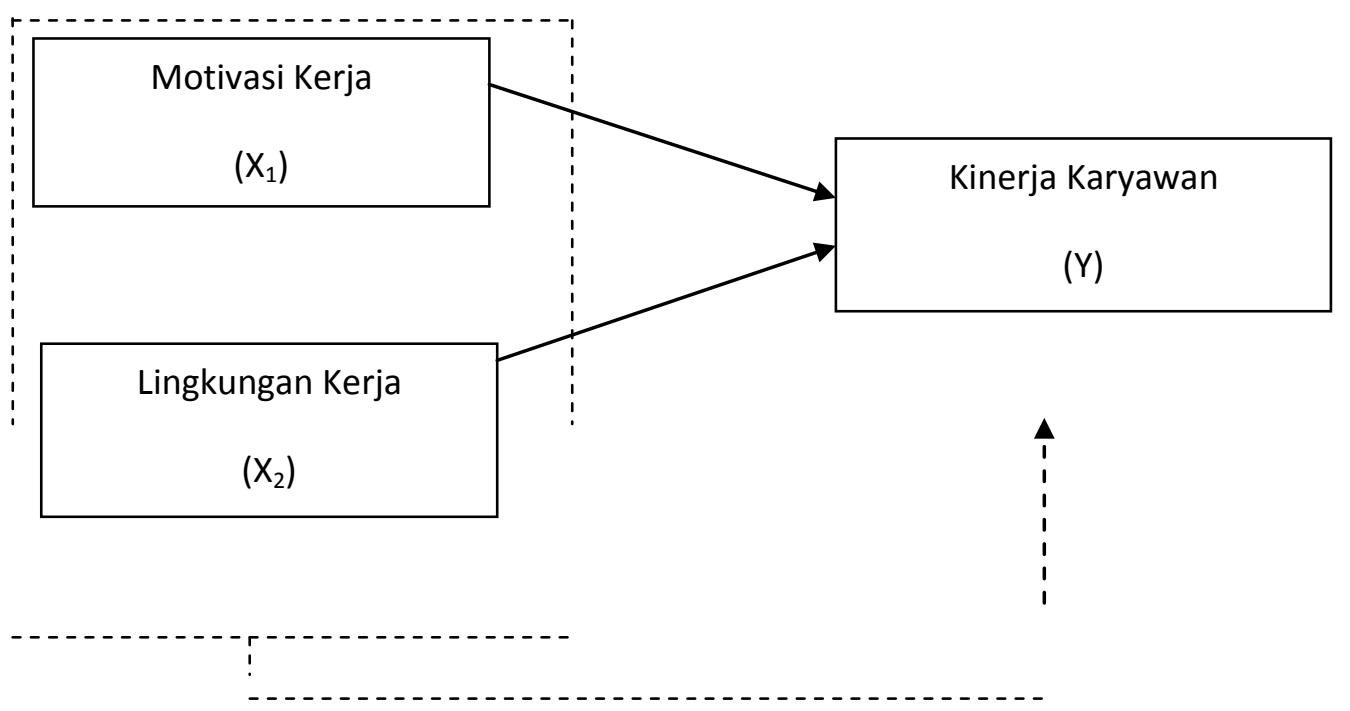

Keterangan : Secara Parsial

Secara Simultan

\section{Skema Kerangka Konseptual Motivasi KerjaDan Lingkungan Kerja Terhadap Kinerja Karyawan}

\section{Hipotesis Penelitian}

Berdasarkan penjabaran di atas, maka peneliti mengajukan hipotesis sebagai berikut :

1. $\mathrm{H}_{0}$ : Tidak terdapat pengaruhmotivasi kerja dan lingkungan kerja yang signifikan secara parsial terhadap kinerja karyawandi Hotel Semagi Muara Bungo.

$\mathrm{H}_{\mathrm{a}}$ : Terdapat pengaruhmotivasi kerja dan lingkungan kerja yang signifikan secara parsial terhadap kinerja karyawandi Hotel Semagi Muara Bungo.
2. $\mathrm{H}_{0}$ :Tidak terdapat pengaruh motivasi kerja dan lingkungan kerja yang signifikan secara simultan terhadap kinerja karyawandi Hotel Semagi Muara Bungo.

. $\mathrm{H}_{\mathrm{a}}$ : Terdapat pengaruh motivasi kerja dan lingkungan kerja yang signifikan secara simultan terhadap kinerja karyawandi Hotel Semagi Muara Bung

\section{Analisis Regresi Berganda}

Hasil analisis regresi linier berganda dari penelitian ini pada tabel berikut ini : 


\section{Analisis Regresi Berganda}

\section{Coefficients $^{\mathrm{a}}$}

\begin{tabular}{|c|c|c|c|c|c|c|c|c|}
\hline \multirow{2}{*}{\multicolumn{2}{|c|}{ Model }} & \multicolumn{2}{|c|}{$\begin{array}{l}\text { Unstandardize } \\
\text { d Coefficients }\end{array}$} & $\begin{array}{c}\text { Standardiz } \\
\text { ed } \\
\text { Coefficien } \\
\text { ts }\end{array}$ & & & \multicolumn{2}{|c|}{$\begin{array}{c}\text { Collinearity } \\
\text { Statistics }\end{array}$} \\
\hline & & B & $\begin{array}{l}\text { Std. } \\
\text { Error }\end{array}$ & Beta & $\mathrm{t}$ & Sig. & $\begin{array}{c}\text { Toleran } \\
\text { ce }\end{array}$ & VIF \\
\hline 1 & (Constant) & $\begin{array}{r}16,92 \\
6\end{array}$ & 3,589 & & $\begin{array}{r}4,71 \\
7\end{array}$ & $\begin{array}{r}0,00 \\
0\end{array}$ & & \\
\hline & $\begin{array}{l}\text { Motivasi } \\
\text { Kerja }\end{array}$ & 1,082 & 0,121 & 0,881 & $\begin{array}{r}8,97 \\
4\end{array}$ & $\begin{array}{r}0,00 \\
0\end{array}$ & 0,810 & $\begin{array}{r}1,23 \\
4\end{array}$ \\
\hline & $\begin{array}{l}\text { Lingkungan } \\
\text { Kerja }\end{array}$ & 0,353 & 0,111 & 0,312 & $\begin{array}{r}3,17 \\
7\end{array}$ & $\begin{array}{r}0,00 \\
3\end{array}$ & 0,810 & $\begin{array}{r}1,23 \\
4\end{array}$ \\
\hline
\end{tabular}

a. Dependent Variable: Kinerja Karyawan

Tabel 4.33 yakni hasil olahan data regresi linier berganda, maka akan dapat disajikan persamaan regresi yaitu sebagai berikut :

$Y=16,926+1,082 X_{1}+0,353 X_{2}+e$

Analisis bentuk persamaan regresi linier berganda diatas sebagai berikut :

- Nilai konstanta (a) sebesar 16,926 artinya apabila variabel motivasi kerja $\left(\mathrm{X}_{1}\right)$ dan lingkungan kerja $\left(\mathrm{X}_{2}\right)$ mempunyai nilai nol, maka $\mathrm{Y}$ (kinerja karyawan) adalah sebesar $16,926$.
- Koefisien regresi $\left(X_{1}\right)=1,082$ ini mempunyai arti bahwa motivasi kerja mempunyai pengaruh signifikan $(0,05)$ terhadap kinerja karyawandan setiap terjadi perubahan variabel kemampuan kerja sebesar 1 satuan, sementara variabel motivasi kerja di asumsikan tetap maka kinerja karyawan akan meningkat sebesar 1,082satuan.

- Koefisien regresi $\left(X_{2}\right)=0,353 I n i$ mempunyai arti bahwa lingkungan kerja mempunyai pengaruh signifikan $(0,05)$ terhadapkinerja 
karyawan dan setiap terjadi perubahan variabel motivasi kerja sebesar 1 satuan sementara variabel lingkungan kerja di asumsikan tetap, makakinerja karyawan akan meningkat sebesar 0,353 satuan.

\section{Hasil Pengujian Hipotesis}

\section{Hasil Uji-t}

Uji-t bertujuan untuk mengetahui besarnya pengaruh masing-masing variabel independen secara individual (parsial) terhadap variabel dependen. Nilai

\section{Coefficients $^{\mathrm{a}}$}

\begin{tabular}{|c|c|c|c|c|c|c|c|c|}
\hline \multirow{2}{*}{\multicolumn{2}{|c|}{ Model }} & \multicolumn{2}{|c|}{$\begin{array}{l}\text { Unstandardize } \\
\text { d Coefficients }\end{array}$} & $\begin{array}{l}\text { Standardiz } \\
\text { ed } \\
\text { Coefficien } \\
\text { ts }\end{array}$ & & & \multicolumn{2}{|c|}{$\begin{array}{c}\text { Collinearity } \\
\text { Statistics }\end{array}$} \\
\hline & & B & $\begin{array}{l}\text { Std. } \\
\text { Error }\end{array}$ & Beta & $\mathrm{t}$ & Sig. & $\begin{array}{c}\text { Toleran } \\
\text { ce }\end{array}$ & VIF \\
\hline 1 & (Constant) & $\begin{array}{r}16,92 \\
6\end{array}$ & 3,589 & & $\begin{array}{r}4,71 \\
7\end{array}$ & $\begin{array}{r}0,00 \\
0\end{array}$ & & \\
\hline & $\begin{array}{l}\text { Motivasi } \\
\text { Kerja }\end{array}$ & 1,082 & 0,121 & 0,881 & $\begin{array}{r}8,97 \\
4\end{array}$ & $\begin{array}{r}0,00 \\
0\end{array}$ & 0,810 & $\begin{array}{r}1,23 \\
4\end{array}$ \\
\hline & $\begin{array}{l}\text { Lingkungan } \\
\text { Kerja }\end{array}$ & 0,353 & 0,111 & 0,312 & $\begin{array}{r}3,17 \\
7\end{array}$ & $\begin{array}{r}0,00 \\
3\end{array}$ & 0,810 & $\begin{array}{r}1,23 \\
4\end{array}$ \\
\hline
\end{tabular}

a. Dependent Variable: Kinerja Karyawan

Berdasarkan hasil uji $\mathrm{t}$ (secara parsial) model regresi linier berganda dari penelitian ini sebagai berikut : $\mathrm{t}$ hitung diperoleh dengan menggunakan Program Software SPSS versi 25.00 for Windows, kemudian akan dibandingkan dengan nilai $\mathrm{t}_{\text {tabel }}$ pada tingkat $\alpha=5 \%$ yakni diperoleh dengan derajat bebas(n adalah jumlah sampel, $\mathrm{k}$ adalah jumlah variabel $\mathrm{x}$ dan y).Menurut (Sugiyono, 2012)df = n - k $(\mathrm{n}=50, \mathrm{k}=3)$, jadi $50-3=47$ dan tingkat signifikasi sebesar alpha $5 \%(0,05: 2$ tailed $=0,025$ maka dapat diperoleh untuk $t_{\text {tabel }}$ sebesar adalah 2,012. 
Uji parsial kemampuan kerja dengan kinerja karyawan diperoleh nilai $t_{\text {hitung }}$ $=8,974$ dan $\mathrm{t}_{\text {tabel }}=2,012$ pada tingkat signifikasi 0,05 maka keputusannya adalah $\mathrm{H}_{0}$ ditolak Ha diterima, maka dapat di simpulkan bahwa motivasi kerja berpengaruh signifikan terhadap kinerja karyawan.

2. Uji parsial lingkungan kerja $\left(X_{2}\right)$ dengan kinerja karyawan (Y)

Uji parsial lingkungan kerja dengan kinerja karyawan diperoleh nilai $t_{h i t u n g}$ $=$
3,117 dan $t_{\text {tabel }}=2,012$ pada tingkat signifikasi 0,05 maka keputusannya adalah $\mathrm{H}_{0}$ ditolak Ha diterima, maka dapat di simpulkan bahwa lingkungan kerja $\left(\mathrm{X}_{2}\right)$ berpengaruh signifikan terhadap kinerja karyawan.

\section{Uji F}

Hasil uji F (secara serentak ) model regresi linier berganda dari penelitian ini sebagai berikut :

\section{ANOVA $^{\mathrm{a}}$}

\begin{tabular}{|l|l|r|r|r|r|r|}
\hline \multicolumn{2}{|l|}{ Model } & $\begin{array}{l}\text { Sum of } \\
\text { Squares }\end{array}$ & df & $\begin{array}{c}\text { Mean } \\
\text { Square }\end{array}$ & F & Sig. \\
\hline 1 & Regression & 408,707 & 2 & 204,353 & 40,599 &, $000^{\mathrm{b}}$ \\
\cline { 2 - 7 } & Residual & 236,573 & 47 & 5,033 & & \\
\cline { 2 - 7 } & & 645,280 & 49 & & & \\
\hline
\end{tabular}

a. Dependent Variable: Kinerja Karyawan

b. Predictors: (Constant), Lingkungan Kerja, Motivasi Kerja

Tabel 4.35 Memperlihatkan nilai $\mathrm{F}$ hitung adalah 40,599dengan tingkat signifikan 0,05. Menurut (Duwi Priyatno, 2009) Df $=\mathrm{n}-\mathrm{k}-1$ atau 50-2-1 = 47 (n adalah jumlah responden dan $\mathrm{k}$ adalah jumlah variabel independen), hasil diperoleh untuk $F_{\text {tabel }}$ sebesar 3,20. Dimana nilai $F_{\text {hitung }} 40,599>F_{\text {tabel }}$ 3,20. Dengan demikian hipotesis $\mathrm{H}_{\mathrm{o}}$ ditolak dan $\mathrm{H}_{\mathrm{a}}$ diterima. Artinya, secara bersama-sama (serentak) variabel-variabel independent yaitumotivasi kerja $\left(\mathrm{X}_{1}\right)$ dan lingkungan kerja $\left(\mathrm{X}_{2}\right)$ berpengaruh signifikan terhadap variabel dependent (Y) yaitu kinerja karyawan.

\section{Pengujian Koefisien Determinasi $\left(\mathbf{R}^{2}\right)$}

Koefisien determinasi $\left(\mathrm{R}^{2}\right)$ bertujuan untuk mengukur seberapa besar 
kemampuan model dalam menerangkan variasi variabel independen. Dalam output
SPSS, koefisien determinasi dapat dilihat pada tabel 4.36 sebagai berikut :

\section{Model Summary ${ }^{\mathrm{b}}$}

\begin{tabular}{|c|c|c|c|c|c|}
\hline Model & $\mathrm{R}$ & R Square & $\begin{array}{c}\text { Adjusted } \\
\text { R } \\
\text { Square }\end{array}$ & $\begin{array}{l}\text { Std. Error } \\
\text { of the } \\
\text { Estimate }\end{array}$ & $\begin{array}{l}\text { Durbin- } \\
\text { Watson }\end{array}$ \\
\hline 1 &, $796^{\mathrm{a}}$ & 0,633 & 0,618 & 2,24354 & 2,274 \\
\hline
\end{tabular}

a. Predictors: (Constant), Lingkungan Kerja, Motivasi Kerja

b. Dependent Variable: Kinerja Karyawan

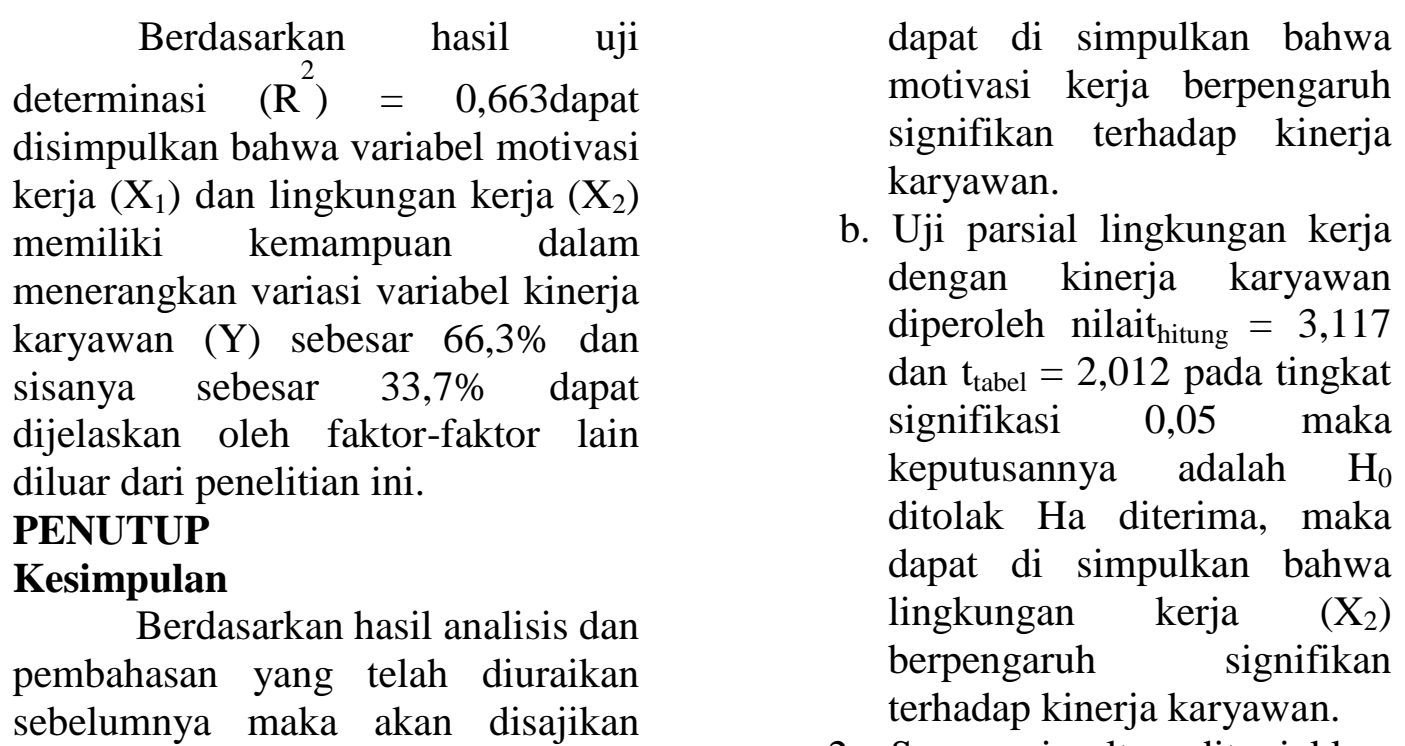
beberapa kesimpulan yaitu sebagai berikut :

1. Secara parsial ditunjukkan bahwa kesimpulan yang diambil dari setiap variabel independent yaitu motivasi kerja $\left(\mathrm{X}_{1}\right)$ dan lingkungan kerja $\left(\mathrm{X}_{2}\right)$ yang dipersepsikan yaitu:

a. Uji parsial motivasi kerja dengan kinerja karyawan diperoleh nilai hitung $=8,974$ dan $\mathrm{t}_{\text {tabel }}=2,012$ pada tingkat signifikasi $0,05 \quad$ maka keputusannya adalah $\mathrm{H}_{0}$ ditolak $\mathrm{Ha}$ diterima, maka
2. Secara simultan ditunjukkan bahwa nilai $\mathrm{F}_{\text {hitung }} 40,599$ $>F_{\text {tabel }}$ 3,20. Dengan demikian hipotesis $\mathrm{H}_{0}$ ditolak dan $\mathrm{H}_{\mathrm{a}}$ diterima. Artinya, secara bersama-sama (serentak) variabel independent yaitumotivasi kerja $\left(\mathrm{X}_{1}\right)$ dan lingkungan kerja $\left(\mathrm{X}_{2}\right)$ berpengaruh signifikan terhadap variabel dependent (Y) yaitu kinerja karyawan

3. Dari hasil pengujian koefisien determinasi maka diperoleh Rsquare sebesar 0,868 angka ini menyatakan bahwa 
variabel motivasi kerja $\left(\mathrm{X}_{1}\right)$ dan lingkungan kerja $\left(\mathrm{X}_{2}\right)$ memiliki kemampuan dalam menerangkan variasi variabel kinerja karyawan sebesar $66,3 \%$ dan sisanya sebesar $33,7 \%$ dapat dijelaskan oleh faktor-faktor lain diluar dari penelitian ini.

Saran

Berdasarkan hasil pembahasan dan analisis sebelumnya maka dapat dikemukan saran-saran sebagai berikut :

1. Variabel motivasi kerja dengan indikator yang terendah adalah prestasi, hendaknya semua karyawan dapat meningkatkan prestasi kerjanya agar pekerjaan dapat terselesaikan secara maksimal.

2. Variabel lingkungan kerjaindikator yang terendah adalah penerangan, hendaknya pimpinan lebih meperhatikan keadaan ruangan kerja karyawan agar karyawan lebih merasa nyaman dalam bekerja.

3. Variabel kinerja karyawan indikator yang terendah adalah kuantitas kerja, yang mana hendaknya karyawan dapat lebih meningkatkan kinerjanya agar pekerjaan dapat menyelesaikan pekerjaan dengan baik.

4. Penelitian ini menggunakan tiga variabel untuk mengukur motivasi kerja dan lingkungan kerja terhadap kinerja karyawan dan bagi peneliti selanjutnya diharapkan mengambil variabel bebas lainnya untuk mengukur variabel kinerja karyawan.

\section{DAFTAR PUSTAKA}

Arikunto, Suharsimi. 2006. Prosedur

Penelitian Suatu Pendekatan

Praktek. Jakarta: Rhineka

Cipta.

Akbar, 2012. Instrumen Perangkat Pembelajaran, PT. Remaja Rosdakarya, Bandung.

Danim,Sudarman.2004. Motivasi,

Kepemimpinan dan Efektivitas Kelompok.

Penerbit Rineka Cipta, Jakarta.

Dessler, Gary, 2008. Manajemen Sumber Daya Manusia. Index, Jakarta

Dwi, Septianto, 2010. Pengaruh Lingkungan Pekerjaan dan Motivasi Kerja Terhadap Kinerja Karyawan pada PT. Patajaya Raya Semarang, JurnalUniversitas Diponegoro Semarang

Fakultas Ekonomi Universitas Muara Bungo, 2014. Buku Pedoman Bimbingan dan Skripsi, Muara Bungo.

Fariz, Ramanda, 2013. Pengaruh lingkungan kerja terhadap kinerja(Studi Pada Karyawan PT. Naraya Telematika Malang),JurnalFakultas Ilmu AdministrasiUniversitas Brawijaya Malang

Handoko, T. Hani, 2001. Manajemen Personal danSumberDayaManusia, BPFE, Yogyakarta. 
Hariandja, Effendi, 2002. Sumber Daya Manusia.Gramedia Widiasarana Indonesia, Jakarta.

Hasibuan, 2008. Manajemen Sumber Daya Manusia, Edisi Revisi. Bumi Aksara, Jakarta.

Kusni, 2002. Manajemen Sumber Daya Manusia,Salemba. Jakarta. Ishak, Arep. 2003. Manajemen Kinerja, PT. Raja Grafindo Persada, Jakarta

Iskandar, Mulia, 2010. Pengaruh Motivasi Kerja Dan Lingkungan Kerja Terhadap Kinerja Karyawan Pada PT. Kawasan Industri Medan, Skripsi Universitas Sumatera Utara Medan

Ika, Rahmatika, 2014. Pengaruh Kemampuan Dan Motivasi KerjaTerhadap Kinerja Karyawan (Studi di Bank BNI Syariah Cabang Bogor, Skripsi Universitas Islam Negeri Syarif HidayatullahJakarta

Malthis, Robert L dan John H. Jackson. 2002,Manajemen Sumber Daya Manusia, Buku I. Salemba Empat, Jakarta.

Mangkunegara, AA. Anwar Prabu, 2005. Evaluasi Kinerja Karyawan. PT Refika Aditama, Bandung.

Munandar, Ashar Sunyoto, 2001. Psikologi Indsutri dan Organisasi,Unifersitas Indonesia (UI Press), Jakarta.
Moenir,

H.A.S, 2008. ManajemenPelayananUmu m di Indonesia: BumiAksara. Jakarta

Nawawi,

Hadari, 2003 ManajemenSumberDayaMa nusiauntukBisnis yang Kompetetif, Gajah Mada University Press, Yogyakarta

Priyatno Duwi, 2009. SPSS Untuk Analisis Korelasi, Regresi, dan Multivariate, Penerbit Gava Media, Yogyakarta.

Robbins, Stephen P., 2008. PerilakuOrganisasi,

EdisiBahasa Indonesia

CetakanKe 2, Prenhallindo, Jakarta.

Sedarmayanti, 2001. Sumber Daya Manusia dan Produktivitas Kerja. Mandar Maju, Bandung.

Septida, Hardiyanti, 2013.Pengaruh Motivasi terhadap Kinerja Karyawan pada PT CIMB Niaga Auto Finance Cabang Lubuk Pakam, Skripsi Universitas Sumatera Utara Medan

Siagian, Sondang, 2008. Manajemen Sumber Daya Manusia, Edisi 1, Cetakan II, Penerbit PT. Bumi Aksara, Jakarta

Soeroto,

Pembangunan 2002.Strategi danPerencanaanKesempata nKerja, Edisi 2, UGM Press, Yogyakarta. 
Sopiah. 2008. Perilaku

Organisasional. Yogyakarta: Andi Offset.

Sri Purwati, 2012. Pengaruh

Motivasi Kerja Karyawan

terhadap Kinerja Karyawan

Pada PT. Anindya Mitra

Intenasional Yogyakarta,

JurnalUniversitas Ahmad

Dahlan

Sudjana, 2001, Metode Statistika,

Edisi Revisi, Cet. 6,: Tarsito,

Bandung

Sukanto, Handoko,. 2010. Manajemen Personalia dan Sumber Daya Manusia. Edisi II. Cetakan keempat belas. Penerbit BPFE, Yogyakarta

Sugiyono, 2012. Statisatika Untuk

Penelitian, Alfabeta, Bandung

Sutrisno Edi, 2009. "Manajemen Sumber Daya Manusia", Kencana Prenada Media Group, Jakarta

Umar, Husein, 2005. Metode Penelitian Untuk Skripsi Dan Tesis Bisnis, Edisi 6 PT. Raj 